\title{
Heat of Decomposition of Potassium Perchlorate
}

\author{
Walter H. Johnson and Alexis A. Gilliland
}

(October 5, 1960)

\begin{abstract}
The heat of decomposition of potassium perchlorate into potassium chloride and oxygen has been determined in a bomb calorimeter. The process may be represented by the equation:

$$
\begin{aligned}
\mathrm{KClO}_{4}(\mathrm{c}) & =\mathrm{KCl}(\mathrm{c})+2 \mathrm{O}_{2}(\mathrm{~g}), \\
\Delta \mathrm{H}^{\circ}\left(25^{\circ} \mathrm{C}\right) & =-4.02 \pm 0.34 \mathrm{kj} / \mathrm{mole}, \\
& =-0.96 \pm 0.08 \mathrm{kcal} / \mathrm{mole} .
\end{aligned}
$$
\end{abstract}

Combination of this datum with the heat of formation of $\mathrm{KCl}(\mathrm{c})$ gives $-103.22 \pm 0.15 \mathrm{kcal} /$ mole for the standard heat of formation of $\mathrm{KClO}_{4}(\mathrm{c})$ at $25{ }^{\circ} \mathrm{C}$.

\section{Introduction}

The thermodynamic properties of alkali and lightmetal perchlorates have become increasingly important during recent years because of their possible use for sources of oxygen in solid-fuel systems. Potassium perchlorate, for example, contains approximately the same quantity of oxygen per unit volume as liquid oxygen at its boiling point. The release of this relatively large amount of oxygen may be effected by heating to about $550{ }^{\circ} \mathrm{C}$. Some of the other perchlorates decompose at considerably lower temperatures.

An accurate value for the heat of decomposition of $\mathrm{KClO}_{4}$ leads to a reliable value for the heat of formation, which serves as a convenient basis for evaluation of the heats of formation of other perchlorates. Potassium perchlorate was chosen because of its stability, ease of purification, and nonhygroscopic character.

\section{Materials}

The potassium perchlorate was reagent-grade material, which was recrystallized twice from water and dried at $135{ }^{\circ} \mathrm{C}$; it was stored in a desiccator over anhydrous magnesium perchlorate. The lot analysis of the material indicated a purity of 99.8 percent; a test for chloride ion with silver nitrate was negative.

The benzoic acid was NBS Standard Sample 39g. Samples of the same material were used for both the calibration and the decomposition experiments.

The filter paper was Whatman No. 42. No attempt was made to dry the paper; instead it was stored at a constant humidity of 40 percent.

The oxygen was freed from traces of combustible materials and of carbon dioxide by passing it successively through (1) a tube packed with copper oxide and heated to $600{ }^{\circ} \mathrm{C}$, and (2) an absorber containing Ascarite. No attempt was made to remove traces of nitrogen or water vapor.

\section{Units of Energy and Molecular Weights}

The unit of energy is the joule; for conversion to the conventional thermochemical calorie, one calorie is taken as 4.1840 joules.

All atomic weights were taken from the 1957 International Table of Atomic Weights [1]. ${ }^{1}$

\section{Apparatus and Procedure}

The calorimeter was of the Dickinson isothermaljacket type which has been described $[2,3]$. The temperature of the calorimeter jacket was controlled within $\pm 0.001{ }^{\circ} \mathrm{C}$ at about $27{ }^{\circ} \mathrm{C}$ by means of a thermostat. The calorimeter temperatures were measured by means of a platinum resistance thermometer and a Mueller-type bridge; timing of the experiments was made by reference to the NBS standard second signals.

The bomb was of the NBS twin-valve type, similar to that which has been described [3]; its volume was $375.5 \mathrm{ml}$. It was modified slightly for the $\mathrm{KClO}_{4}$ decomposition experiments in that two crucibles were used, one being mounted about $1 \mathrm{~cm}$ directly above the other. The $\mathrm{KClO}_{4}$ sample was weighed into the upper crucible. The benzoic acid pellet, approximately $0.6 \mathrm{~g}$, was placed, in the lower crucible, on a strip of filter paper which extended out over the lip of the crucible. Ignition was accomplished by means of an electrically heated, iron-wire fuse which was placed in contact with the protruding end of the paper strip. One $\mathrm{ml}$ of water was placed in the bomb, which was then sealed, flushed with oxygen, and filled with oxygen to a pressure of 30 atm at $25^{\circ} \mathrm{C}$.

The details of the calorimetric procedure have been described $[3,4]$. The heat evolved by the burning of the benzoic acid was sufficient to decompose the $\mathrm{KClO}_{4}$, leaving a fused mass of $\mathrm{KCl}$ in the crucible.

\footnotetext{
${ }_{1}$ Figures in brackets indicate the literature references at the end of this paper.
} 
In each case, a small portion of the $\mathrm{KClO}_{4}$ was blown out of the crucible during the decomposition; this made necessary a determination of the quantity of decomposition by analysis of the combustion products. The total mass of carbon dioxide was determined by collecting the dry gas in a weighed absorption tube containing Ascarite. The material remaining in the bomb was washed into a flask and the amount of chloride ion determined by titration with standard $\mathrm{AgNO}_{3}$, using fluorescein as the indicator [5].

The heat of combustion of the filter paper was determined in two separate experiments in which about $0.8 \mathrm{~g}$ of the paper was pressed into a wad, placed in the bomb, and burned in the usual manner. The mass of carbon dioxide produced by the combustion was determined as described above.

The calorimeter system was calibrated by a series of combustion experiments with benzoic acid, NBS Standard Sample 39g. The mass of benzoic acid was about $0.55 \mathrm{~g}$ in each instance; this value was chosen because it was sufficient for the $\mathrm{KClO}_{4}$-decomposition experiments and duplication, as nearly as possible, of the initial and final calorimeter temperatures was desirable.

\section{Results and Calculations}

The results of the calibration experiments with benzoic acid are given in table 1 , where $\Delta R c$ is the corrected rise in temperature of the calorimeter system (as measured on the particular thermometer and bridge [6]), $m_{s}$ is the mass of benzoic acid corrected to weight in vacuo, $q_{i}$ is the ignition energy from combustion of the iron-wire fuse, and $q_{N}$ is the energy evolved by the formation of nitric acid from traces of nitrogen in the bomb. The quantity $W C$ is the Washburn correction [6, 7], applied here to convert the reactants and products from their thermodynamic standard states into the actual conditions of the bomb process; this correction may be defined by the relationship $W C=\Delta E^{\circ}-\Delta E_{B}$. The quantity $\Delta e$ is the deviation in the energy equivalent of the actual calorimeter system from that of the "standard" system; this value includes the heat capacity of the benzoic acid sample, a correction to the mean temperature of the calorimeter $\left(26.5{ }^{\circ} \mathrm{C}\right)$ for the heat capacity of the calorimeter system, and a correction to $27.0{ }^{\circ} \mathrm{C}$ for $\Delta \mathrm{Cv}$ of the reaction of combustion.

TABLE 1. Results of the calibration experiments with benzoic acid

\begin{tabular}{|c|c|c|c|c|c|c|c|}
\hline $\begin{array}{c}\text { Experiment } \\
\text { No. }\end{array}$ & $\Delta R c$ & $m_{8}$ & $q_{i}$ & $q_{N}$ & $W C$ & $\Delta e$ & $E_{8}$ \\
\hline $\begin{array}{l}1 \\
2 \\
3 \\
4 \\
5\end{array}$ & $\begin{array}{c}\text { ohm } \\
0.114219 \\
.103961 \\
.103602 \\
.101401 \\
.101426\end{array}$ & $\begin{array}{c}g \\
0.61115 \\
.55620 \\
.55427 \\
.54238 \\
.54252\end{array}$ & $\begin{array}{l}j \\
34.6 \\
34.6 \\
34.0 \\
35.7 \\
35.6\end{array}$ & $\begin{array}{l}j \\
0.9 \\
1.1 \\
1.2 \\
0.4 \\
1.0\end{array}$ & $\begin{array}{l}j \\
11.8 \\
10.9 \\
10.8 \\
10.3 \\
10.5\end{array}$ & $\begin{array}{r}\text { j/ohm } \\
3.9 \\
7.2 \\
7.2 \\
7.1 \\
7.1\end{array}$ & $\begin{array}{l}j / \text { ohm } \\
141728.3 \\
141743.2 \\
141736.5 \\
141720.4 \\
141728.8\end{array}$ \\
\hline \multicolumn{7}{|c|}{$\begin{array}{l}\text { Mean } \\
\text { Standard deviation of the mean }\end{array}$} & $\begin{array}{r}141731.4 \\
\pm 3.9\end{array}$ \\
\hline
\end{tabular}

The heat of combustion of benzoic acid for the standard bomb-process, $-\Delta E_{B}\left(25^{\circ} \mathrm{C}\right)$, was taken as $26433.8 \mathrm{j} / \mathrm{g}$. This value was corrected to give $-\Delta E^{\circ}\left(25^{\circ} \mathrm{C}\right)=26413.1$ for the heat of combustion at constant volume, for the reactants and products in their thermodynamic standard states. A correction of $1.9 \mathrm{j} / \mathrm{g}$ made for $\Delta \mathrm{Cv}$ of the combustion reaction gave the following value for benzoic acid:

$$
\Delta E^{\circ}\left(27^{\circ} \mathrm{C}\right)=-26411.2 \mathrm{j} / \mathrm{g}
$$

The energy equivalent of the "standard" calorimetric system for the temperature interval of 26 to $27^{\circ} \mathrm{C}$ is obtained by:

$$
E_{s}\left(27{ }^{\circ} \mathrm{C}\right)=\frac{26411.2 m_{s}+q_{i}+q_{N}+W C}{\Delta R c}-\Delta e .
$$

The results of the experiments on the combustion of filter paper are given in table 2 . The value for the standard combustion process at constant volume is given by:

$-\Delta E^{\circ}\left(27^{\circ} \mathrm{C}\right)$

$$
=\left[\left(E_{s}+\Delta e\right) \Delta R c-q_{i}-q_{N}+q_{t}-W C\right] / m_{f p}
$$

The quantity $q_{t}$ is a correction for the thermal coefficient of the combustion process to correct the experimental results to $27{ }^{\circ} \mathrm{C}$. The value obtained for $\Delta E^{\circ}\left(27^{\circ} \mathrm{C}\right)$ was $-16670 \mathrm{j} / \mathrm{g}$.

The results of the experiments on the decomposition of $\mathrm{KClO}_{4}$ are given in table 3 . The value obtained for the standard constant-volume process at $27{ }^{\circ} \mathrm{C}$ is given by the relationship:

$$
\begin{aligned}
-\Delta E^{\circ}\left(27{ }^{\circ} \mathrm{C}\right) \\
=\frac{\left(E_{s}+\Delta e\right) \Delta R c-q_{i}-q_{N}+q_{t}-q_{f p}-q_{b a}-W C}{\mathrm{~mole} \mathrm{KClO}_{4}} .
\end{aligned}
$$

\begin{tabular}{|c|c|c|c|c|c|c|c|c|}
\hline $\begin{array}{c}\text { Experiment } \\
\text { No. }\end{array}$ & $\Delta R c$ & $\Delta e$ & $q_{i}$ & $q_{N}$ & $q_{t}$ & $W C$ & $m_{f p}$ & $-\Delta \mathrm{E}^{\circ}\left(27^{\circ} \mathrm{C}\right)$ \\
\hline & ohm & j/ohm & $j$ & $j$ & $j$ & $j$ & $g$ & $j / g$ \\
\hline $\begin{array}{l}1 \\
2 \\
2\end{array}$ & $\begin{array}{r}0.098558 \\
.091101\end{array}$ & $\begin{array}{l}16.6 \\
17.1\end{array}$ & $\begin{array}{l}31.4 \\
32.2\end{array}$ & $\begin{array}{l}0.7 \\
1.4\end{array}$ & $\begin{array}{r}-0.2 \\
0.0\end{array}$ & $\begin{array}{r}10.5 \\
9.6\end{array}$ & $\begin{array}{r}0.83479 \\
.77271\end{array}$ & $\begin{array}{l}16684.0 \\
16656.0\end{array}$ \\
\hline \multicolumn{8}{|l|}{ Mean. } & 16670.0 \\
\hline
\end{tabular}

TABLE 2. Results of the experiments on the combustion of

\begin{tabular}{|c|c|c|c|c|c|c|c|c|c|c|}
\hline $\begin{array}{c}\text { Experiment } \\
\text { No. }\end{array}$ & $\Delta R c$ & $\Delta e$ & $q_{i}$ & $q_{N}$ & $q_{t}$ & $q_{f p}$ & $q_{b a}$ & $W C$ & $\mathrm{KClO}_{4}$ & $\begin{array}{l}-\Delta \mathrm{E}^{\circ} \\
\left(27^{\circ} \mathrm{C}\right)\end{array}$ \\
\hline & $o h m$ & $\mathrm{j} / \mathrm{ohm}$ & $j$ & $j$ & $j$ & $j$ & $j$ & $j$ & mole & $\mathrm{kj} / \mathrm{mole}$ \\
\hline & 0.114725 & 45.6 & 32.4 & 0.9 & 0.1 & 216.4 & 15873.9 & 21. 9 & 0.01336 & 8. 980 \\
\hline & .104967 & 45.0 & 34.6 & .9 & .1 & 226.9 & 14524.5 & 17. 5 & .00944 & 8. 214 \\
\hline & .108221 & 37.3 & 32.5 & .9 & .1 & 287. 7 & 14881.6 & 25.5 & .01301 & 8.782 \\
\hline & .113302 & 42.5 & 32.6 & .9 & .1 & 269. 6 & 15620.3 & 21. 8 & .01334 & 8.858 \\
\hline & .114737 & 38.0 & 33.3 & .9 & .1 & 223.9 & 15848.5 & 23.3 & .01496 & 9.117 \\
\hline & .114943 & 37.5 & 32.0 & .9 & .1 & 227.5 & 15877.3 & 22.9 & .01436 & 9.390 \\
\hline & .114876 & 37.5 & 35.0 & .9 & .1 & 231. 2 & 15866.5 & 22.8 & .01422 & 9.110 \\
\hline $8 \ldots \ldots$ & .114358 & 37.5 & 33.5 & .9 & .1 & 184.2 & 15852.8 & 21. 2 & .01244 & 9. 639 \\
\hline \multicolumn{10}{|c|}{ Mean } & 9. 011 \\
\hline \multicolumn{10}{|c|}{ Standard deviation of the mean } & \pm 0.151 \\
\hline
\end{tabular}
filter paper

TABLE 3. Results of the experiments on the decomposition of $\mathrm{KClO}_{4}$ 
and may be represented by the equation:

$$
\mathrm{KClO}_{4}(\mathrm{c})=\mathrm{KCl}(\mathrm{c})+2 \mathrm{O}_{2}(\mathrm{~g}),
$$

$$
\Delta E^{\circ}\left(27^{\circ} \mathrm{C}\right)=-9.01 \pm 0.30 \mathrm{kj} / \text { mole. }
$$

This result was corrected to constant pressure at $27^{\circ} \mathrm{C}$, with $\mathrm{R}=8.3147 \mathrm{j} / \mathrm{deg}$ mole;

$$
\begin{aligned}
\Delta \mathrm{H}^{\circ}\left(27^{\circ} \mathrm{C}\right) & =\Delta E^{\circ}+\Delta(P V)=\Delta E^{\circ}+\Delta n R T \\
& =-4.02 \pm 0.30 \mathrm{kj} / \text { mole }
\end{aligned}
$$

For eq (1) $\Delta \mathrm{C}_{\mathbf{p}}=-0.08 \mathrm{j} / \mathrm{deg}$ mole [8]; thus

$$
\begin{aligned}
\Delta \mathrm{H}^{\circ}\left(25^{\circ} \mathrm{C}\right) & =-4.02 \pm 0.40 \mathrm{kj} / \mathrm{mole} \\
& =-0.96 \pm 0.10 \mathrm{kcal} / \mathrm{mole} .
\end{aligned}
$$

The uncertainty assigned to this value has been obtained by combining twice the standard deviations of the mean of the calibration and decomposition experiments with reasonable estimates for other errors.

The heat of formation of $\mathrm{KCl}(\mathrm{c})$ has been taken as $-104.175 \mathrm{kcal} / \mathrm{mole}[8]$. From this value and the heat of decomposition corresponding to eq (1) the following value has been obtained:

$\mathrm{KClO}_{4}(\mathrm{c}), \Delta \mathrm{Hf}^{\circ}\left(25^{\circ} \mathrm{C}\right)=-103.22 \pm 0.10 \mathrm{kcal} / \mathrm{mole}$.

\section{Discussion}

Berthelot and Vieille [9] determined the difference between the heat of explosion of ammonium picrate and that of an ammonium picrate-potassium perchlorate mixture, and also the difference between the heat of explosion of potassium picrate and that of a potassium picrate-potassium perchlorate mixture. They obtained $7.5 \mathrm{kcal} / \mathrm{mole}$ for the decomposition of $\mathrm{KClO}_{4}$ according to eq (1).

Hofmann and Marin [10] burned a mixture of paraffin and potassium perchlorate and obtained $\Delta \mathrm{E}\left(25{ }^{\circ} \mathrm{C}\right)=-1.73 \mathrm{kcal} / \mathrm{mole}$ for the constantvolume process corresponding to eq (1). Correction of their value for $\Delta(P V)$ gives $\Delta \mathrm{H}\left(25^{\circ} \mathrm{C}\right)$ $=-0.55 \mathrm{kcal} / \mathrm{mole}$.

Rossini, Wagman, Evans, Levine, and Jaffe [8] used the data of Hofmann and Marin because they were the only data available which were reasonably compatible with the data on potassium chlorate and on perchloric acid.

\section{References}

[1] E. Wichers, J. Am. Chem. Soc. 80, 4121 (1958).

[2] J. R. Eckman and F. D. Rossini, BS J. Research 3, 597 (1929) RP111.

[3] E. J. Prosen and F. D. Rossini, J. Research NBS 27, 289 (1941) RP1420.

[4] W. H. Johnson, E. J. Prosen, and F. D. Rossini, J. Research NBS 35, 141 (1945) RP1665.

[5] I. M. Kolthoff, Chem. Revs. 16, 87 (1935).

[6] E. J. Prosen, Chapter 6 in Experimental thermochemistry, F. D. Rossini, ed. (Interscience Publishers, Inc., New York, N.Y., 1956).

[7] E. W. Washburn, BS J. Research 10, 525 (1933) RP546.

[8] F. D. Rossini, D. D. Wagman, W. H. Evans, S. Levine, and I. Jaffe, Selected values of chemical thermodynamic properties, NBS Circ. 500, (U.S. Government Printing Office, Washington 25, D.C., 1952).

[9] M. Berthelot and P. Vieille, Ann. chim. et phys. [5] 27, 225 (1882).

[10] K. A. Hofmann and P. H. Marin, Sitzber. preuss. Akad. Wiss. Physik, math. Kl, 1932, 448.

(Paper 65A1-84) 